This item was submitted to Loughborough's Research Repository by the author.

Items in Figshare are protected by copyright, with all rights reserved, unless otherwise indicated.

\title{
Dynamic behavior of advanced Ti alloy under impact loading: experimental and numerical analysis
}

\section{PLEASE CITE THE PUBLISHED VERSION}

http://www.ttp.net/1660-9336.html

\section{PUBLISHER}

(c) Trans Tech Publications Inc.

\section{VERSION}

AM (Accepted Manuscript)

\section{LICENCE}

CC BY-NC-ND 4.0

\section{REPOSITORY RECORD}

Demiral, Murat, Anish Roy, and Vadim V. Silberschmidt. 2019. "Dynamic Behavior of Advanced Ti Alloy Under Impact Loading: Experimental and Numerical Analysis”. figshare. https://hdl.handle.net/2134/8730. 
This item was submitted to Loughborough's Institutional Repository (https://dspace.lboro.ac.uk/) by the author and is made available under the following Creative Commons Licence conditions.

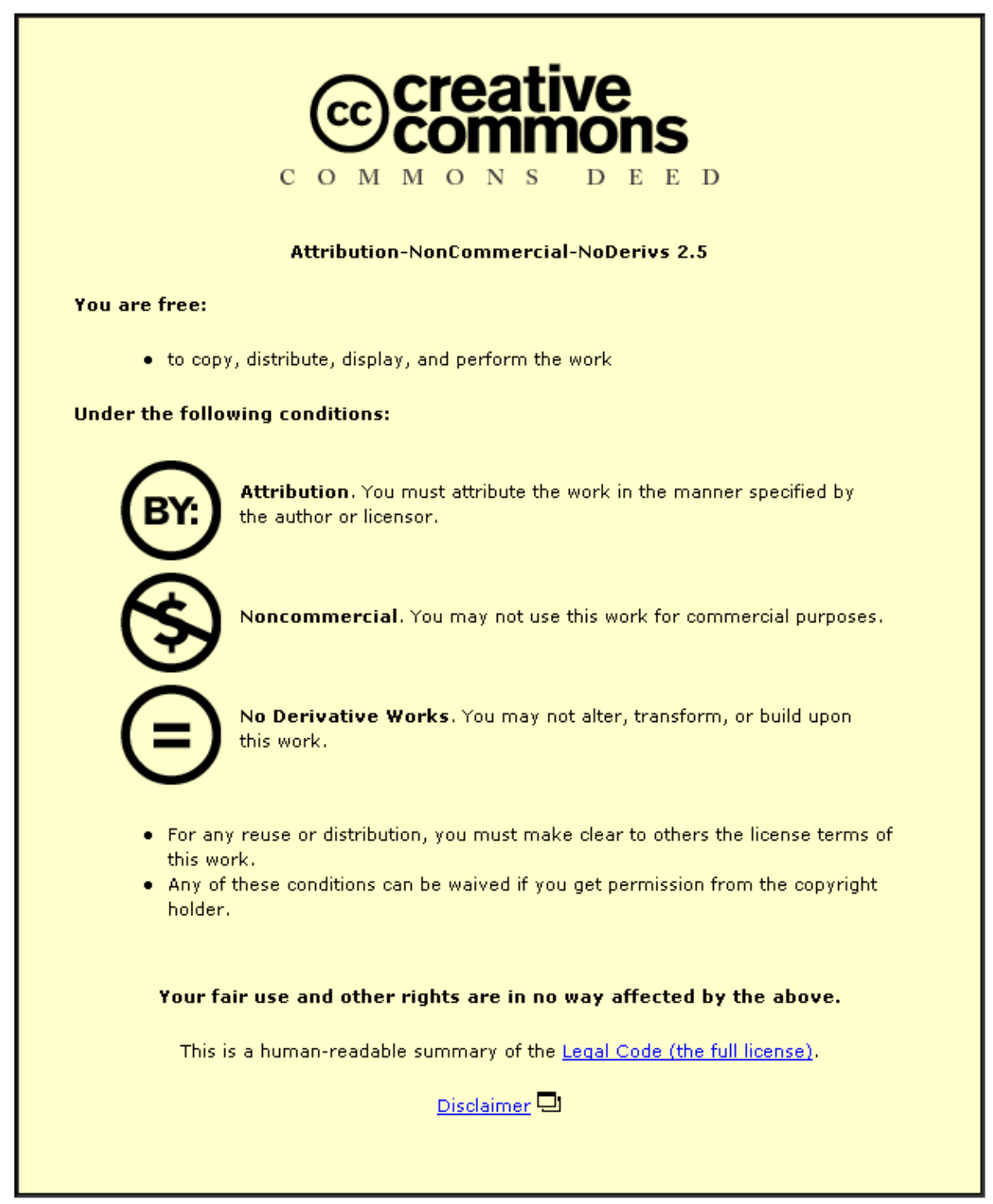

For the full text of this licence, please go to: http://creativecommons.org/licenses/by-nc-nd/2.5/ 


\title{
Dynamic behavior of advanced Ti alloy under impact loading: Experimental and numerical analysis
}

\author{
Murat Demiral $^{\mathrm{a}}$, Anish Roy ${ }^{\mathrm{b}}$, Vadim V. Silberschmidt ${ }^{\mathrm{c}}$ \\ Wolfson School of Mechanical and Manufacturing Engineering, Loughborough University, LE11 \\ 3TU, Leicestershire, UK.

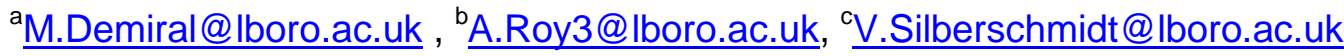

Keywords: Split Hopkinson Pressure Bar; Numerical analysis; Ti-based alloy

\begin{abstract}
Industrial applications of Ti-based alloys, especially in aerospace, marine and offshore industries, have grown significantly over the years primarily due to their high strength, light weight as well as good fatigue and corrosion-resistance properties. A combination of experimental and numerical studies is necessary to predict a material behavior of such alloys under high strain-rate conditions characterized also by a high level of strains accompanied by high temperatures. A Split Hopkinson Pressure Bar (SHPB) technique is a commonly used experimental method to characterize a dynamic stress-strain response of materials at high strain rates. In a SHPB test, the striker bar is shot against the free end of the incident stress bar, which on impact generates a stress pulse propagating in the incident bar towards the specimen sandwiched between the incident and transmitted bars. An experimental study and a numerical analysis based on a three-dimensional finite element model of the SHPB experiment are performed in this study to assess various features of the underlying mechanics of deformation processes of the alloy tested at high-strain and -strainrate regimes.
\end{abstract}

\section{Introduction}

Titanium alloy Ti-15V-3Cr-3Al-3Sn, commercially known as Ti-15-3-3-3, is a metastable beta alloy. Since these alloys are hard to machine, there is an obvious demand to develop simulation tools in order to analyse the material's behaviour during machining. Since high levels of strains and strain rates accompanied by high temperatures characterize the deformation process in machining, the material properties at these extreme conditions are needed. The Split Hopkinson Pressure Bar (SHPB) technique is a commonly used experimental method at strain rates between $10^{2}$ and $10^{4} \mathrm{~s}^{-1}$ under varying temperature regimes to characterize the dynamic stress-strain response of materials [2].

The procedure followed in SHPB to obtain the strain, strain-rate and flow stress in the specimen is based on some basic assumptions. Firstly, the one-dimensional elastic-wave propagation theory is assumed to be adequate to describe the wave propagation in the bars. Secondly, the stress and strain fields in the specimen are assumed to be homogeneous in the axial direction, and, finally, the radial inertial effects of the specimen as well as friction effects are considered to be negligible. Those assumptions have been extensively studied in past decades and a review of the consequence of these assumptions on the accuracy and relevance of SHPB is given in [3]. The studies carried out in [4-7] demonstrated that stresses and strains were not axially uniform, especially at the early stage of the experiment necessitating critical reassessment of the validity of the assumptions in the determination of the mechanical response of Ti-15-3-3-3. A computational study on a threedimensional finite element model of the SHPB experiment is performed to assess various features of the underlying mechanics of deformation processes at high-strain and -strain-rate regimes. 


\section{Split Hopkinson Bar Technique}

A schematic of a compression SHPB system is presented in Fig. 1. The system consists of two 1.2 $\mathrm{m}$-long maraging-steel rods with a diameter of $21.77 \mathrm{~mm}$ (incident and transmitter bar) and a striker bar made of the same material and with the same diameter [8].

The test was performed by impacting the striker bar on the free end of the incident bar and thus producing a compressive stress pulse into it. To eliminate high-frequency oscillations in the loading pulse and to improve the specimen`s deformation at a constant strain rates, especially at lower strains, an annealed copper pulse shaper with $0.1 \mathrm{~mm}$ thickness was placed on the impact end of the incident bar (Fig. 1).

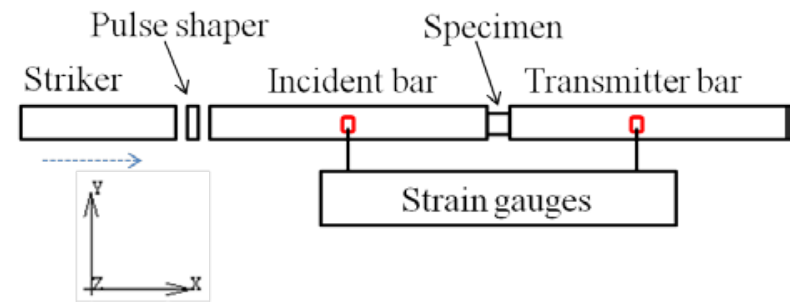

Figure 1: Schematic of SHPB technique [9]

When the stress pulse reached the interface between the bar and the specimen, a part of the wave was transmitted to the transmitter bar while part of it was reflected back into the incident bar as a wave of tension. The loaded specimen underwent a dynamic elasto-plastic deformation as the stress pulse travelled through it. Typically, several reverberations within the specimen were required to build up an equilibrium stress. Axial components of the stress, strain, and strain rate in the specimen can be calculated from the three time-dependent elastic stress pulses, namely, incident, reflected and transmitted pulses, measured from the pressure bars using strain gauges and recorded with a digital oscilloscope. According to the 1-wave analysis of SHPB data, equations for strain rate, strain and stress are calculated as follows [10]:

$$
\begin{aligned}
& \dot{\varepsilon}(t)=-\frac{2 C}{L_{S}} \varepsilon_{R}(t), \\
& \varepsilon(t)=-\frac{2 C}{L_{S}} \int_{0}^{t} \varepsilon_{R}(t), \\
& \sigma(t)=\frac{A_{B} E_{B}}{A_{S}} \varepsilon_{T}(t),
\end{aligned}
$$

where $C$ represents the elastic wave velocity, $L_{S}$ corresponds to the initial length of the specimen, $A_{B}$ and $A_{S}$ are the cross-sectional areas of the bars and the specimen, respectively, and $E_{B}$ is the Young's modulus of the bar material.

The plastic response of Ti-15-3-3-3 under impact conditions was characterized by SHPB test at strain rates of up to $3500 \mathrm{~s}^{-1}$ and at room temperature and $600^{\circ} \mathrm{C}$ (Figs. 2 and 4 ). The behaviour of the material at elevated temperature needs to be characterized as sufficient heat is generated during the machining process of alloy which would ultimately affect the mechanical response of the workpiece. The tests at elevated temperatures were carried out in a thermal chamber. At $600^{\circ} \mathrm{C}$ the dynamic effects of material response is amplified and hence stress-strain curve greatly oscillates corresponding to the elastic waves going back and forth during the deformation process of the specimen. Compression tests were performed on a servo-hydraulic testing machine for quasi-static conditions. The length to diameter ratio of the specimens, wire-cut from an as-received ingot to cylinders of diameter $8 \mathrm{~mm}$ and length $6 \mathrm{~mm}$, is between 0.5 and 1, what is considered an optimum range to minimize effects of specimen friction and inertia [11]. The properties and dimensions of the materials used in the experiments and in finite element simulations are presented in Tables 1-3. The stress-strain responses obtained from the experiments are given in Fig. 2. 
Table 1: Properties of maraging steel (W 720) bars

\begin{tabular}{|c|c|}
\hline Length of striker [mm] & 200 \\
\hline $\begin{array}{c}\text { Length of incident and } \\
\text { transmitter bars [mm] }\end{array}$ & 1200 \\
\hline Diameter of bars [mm] & 21.77 \\
\hline Young's modulus [GPa] & 198 \\
\hline Yield Strength [MPa] & 1850 \\
\hline Poisson's ratio & 0.329 \\
\hline Density [kg m-3] & 8470 \\
\hline Uniaxial wave velocity [m s-1] & 4835 \\
\hline
\end{tabular}

Table 2: Properties of Ti-alloy specimen

\begin{tabular}{|c|c|}
\hline Length [mm] & 6 \\
\hline Diameter [mm] & 8 \\
\hline Young's modulus [GPa] & 87 \\
\hline Poisson's ratio & 0.3 \\
\hline Density [kg m-3] & 4900 \\
\hline Conductivity [ $\mathrm{W} \mathrm{m}^{-1} \mathrm{~K}^{-1}$ ] & 8.08 \\
\hline
\end{tabular}

Table 3: Properties of copper pulse shaper

\begin{tabular}{|c|c|}
\hline Thickness [mm] & 0.1 \\
\hline Diameter [mm] & 8 \\
\hline Young's modulus [GPa] & 110 \\
\hline Poisson's ratio & 0.343 \\
\hline Density [kg m-3] & 8000 \\
\hline Ultimate tensile strength [MPa] & 210 \\
\hline Yield strength [MPa] & 33.3 \\
\hline Plastic zone slope factor [GPa] & 1.6 \\
\hline
\end{tabular}

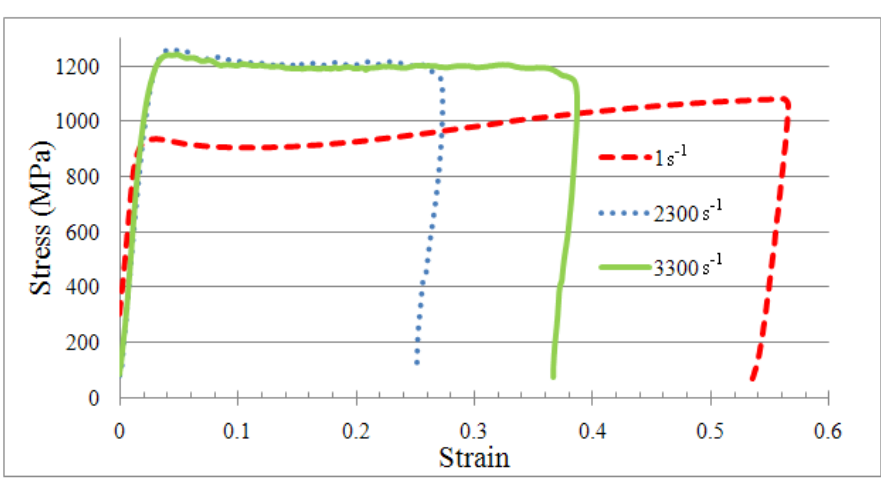

Figure 2: Stress-strain diagrams of Ti15V3Cr3Al3Sn obtained from split-Hopkinson pressure bar tests (strain-rates $2300 \mathrm{~s}^{-1} 3300 \mathrm{~s}^{-1}$ ) and quasi-static compression tests (strain-rate $1 \mathrm{~s}^{-1}$ ) at room temperature $\left(20^{\circ} \mathrm{C}\right)$

\section{Finite-element modeling}

A numerical analysis was carried out to study the details of the underlying mechanics during the deformation process in the SHPB experiment. The commercial general-purpose finite element code MSC.Marc [12] with an implicit dynamic transient operator was used for a three-dimensional finite element model of the experiment (Fig. 3). All the bars, the pulse shaper and the tested workpiece were meshed with eight-noded, isoparametric, hexahedral elements (Element type 7). The incident and transmitter bars were discretized with 5760 elements each, the striker bar with 960 elements and the pulse shaper with 2800 elements. Initially, an element-size-sensitivity analysis was carried out for the workpiece, and an element size of $0.2 \mathrm{~mm}$ was found to be optimal for our numerical studies. The initial number of elements used to mesh the workpiece was 75600 . In the numerical analysis, an initial velocity of $24.3 \mathrm{~m} \mathrm{~s}^{-1}$ is considered to be the striker velocity hitting the incident bar, which roughly corresponds to a strain rate $(\dot{\varepsilon})$ of $2700 \mathrm{~s}^{-1}$. As the interface between incident bar-specimen and specimen-transmitter bar is well lubricated in experiments, frictionless contact 
condition is assumed in the numerical modelling and the effects of dynamic friction is assumed to be negligible. The current FE model is thermomechanically coupled and it is assumed that all the plastic work in the workpiece is converted into thermal energy.

\section{Material model}

The nonlinear strain-rate sensitive material model was used to represent the material behaviour of specimen in our numerical simulations and the magnitude of stress values for high strain values are limited to the ultimate tensile stress (UTS) for the corresponding strain rates (Fig. 4). To characterize the stress-strain data for higher strain rates beyond the experimentally characterized ones, a $20 \%$ offset from the corresponding values for $\dot{\varepsilon}=3300 \mathrm{~s}^{-1}$ was taken (Fig. 4). The temperature-dependent thermal expansion coefficient and the specific heat value of the workpiece material $\left(C_{p}\right)$ used in the simulations can be found in ref. [13]. A piece-wise linear elasto-plastic material model is used to represent the material behaviour of the pulse shaper in simulations.

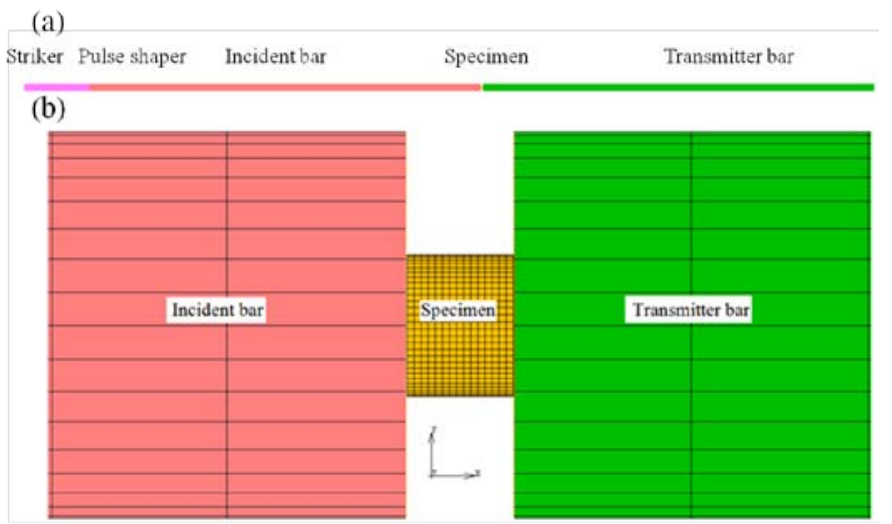

Figure 3: FE model of the SHPB experiment (a) and zoomed part with specimen tested (b)

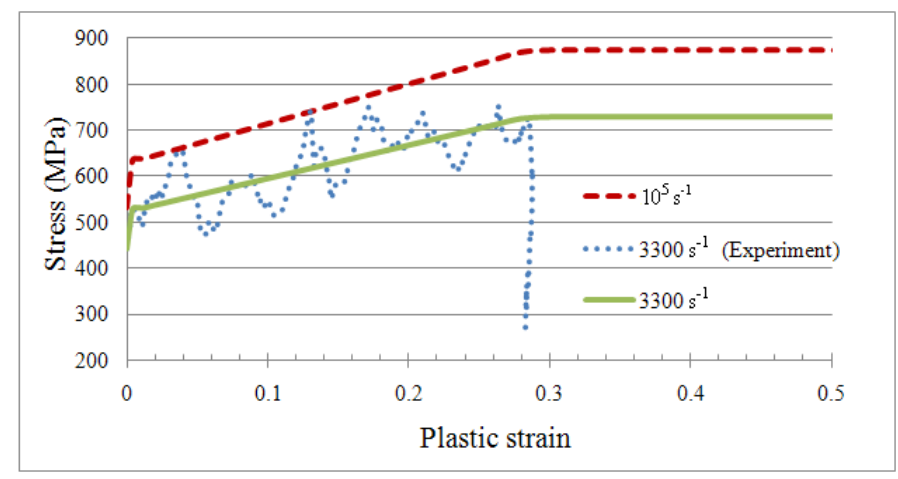

Figure 4: Modified strain rate-sensitive material model $\left(600^{\circ} \mathrm{C}\right)$

\section{Numerical results and discussion}

The analysis of the incident, transmitted and reflected waves clarifies the uniaxial stress-strain behaviour of the specimen. The axial strain values measured by strain gages, located at the middle span of the bars, are compared with the strain values obtained at the same location in numerical analysis (see Fig. 1).

The experimental and numerical results characterising the axial strain waves match reasonably well for the incident, transmitted and reflected waves (Fig. 5). The incident and reflected waves as observed in the incident bar is immune to the deformation of the workpiece (and consequently the material response of the workpiece). This explains the good match of the experiments with our simulations, which also implies that the material response of the incident bar is reasonably modelled by an elasto-plastic material behaviour. However, the mechanically softer material of the workpiece has other complicating factors which give rise to the mismatch with the experiments for the transmitter bar. Other possible factors responsible for minor deviations of the simulation results 
from the experimental data are (dynamic) friction between the workpiece and the pressure bars, longitudinal wave dispersion in the pressure bars, radial inertia in the workpiece, and impedance mismatch of the bars with the specimen.

The numerical results demonstrate that an inhomogeneous deformation behaviour is observed in the workpiece at the early stages of the compression process (Fig. 6). A homogeneous stress state is reached in the workpiece at approxi. $1.8 \%$ plastic strain.

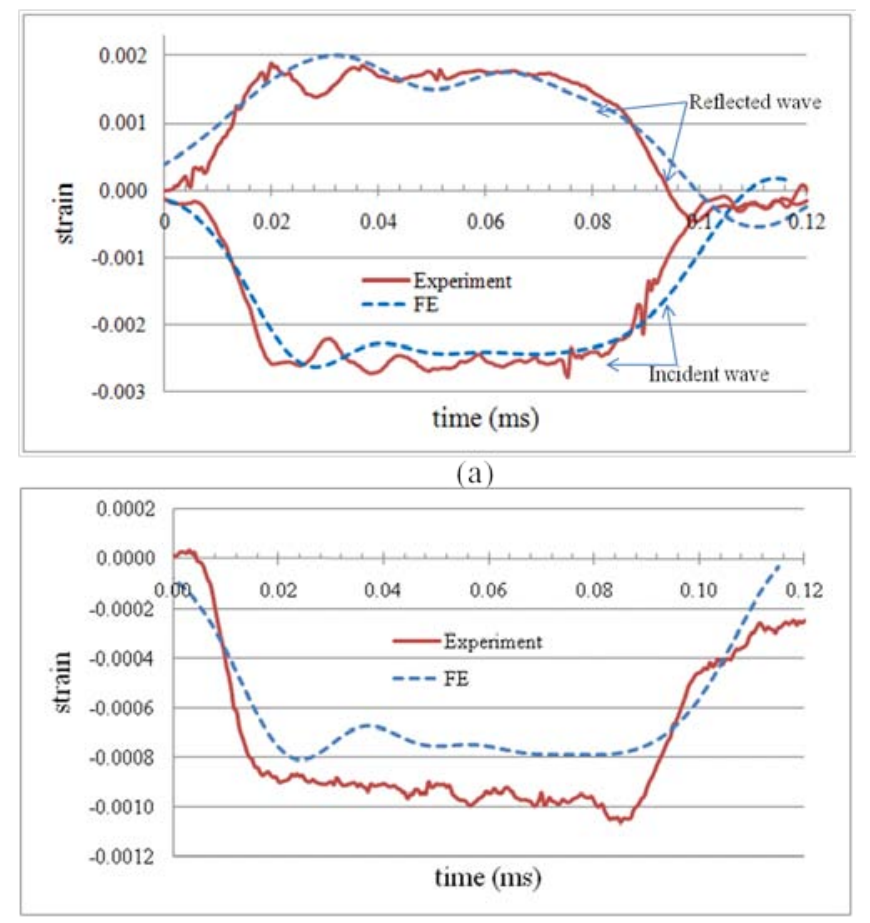

(b)

Figure 5: Comparison of strain evolution at bar mid-span: (a) incident and reflected stress waves; (b) transmitted stress wave

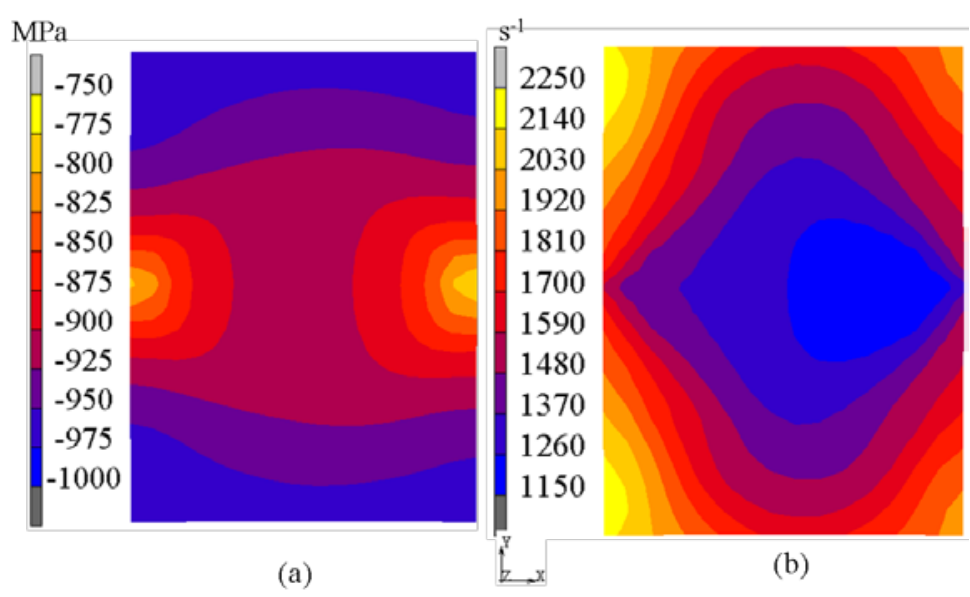

Figure 6: Distribution of axial stress (a) and strain rate (b) in central cross sectional plane normal to the radial direction of specimen at $t=12.5 \mu$ s after first contact between incident bar and specimen

The magnitude of axial stress in the central cross sectional plane normal to the radial direction of the workpiece at $t=12.5 \mu$ s after first contact between incident bar and specimen vary by $250 \mathrm{MPa}$ (Fig. 6a). The values of equivalent plastic strain rate at the same cross sectional plane of the workpiece reveals the inhomogeneity as well (Fig. 6b). These may be of some concern with regard to the fundamental assumption of homogeneity of the fields during the entire deformation history. 


\section{Conclusion}

The deformation behaviour of a titanium alloy under high-strain and -strain-rate deformation regimes was studied using 3-D finite-element simulations of the split-Hopkinson pressure bar test. To obtain the mechanical stress-strain response of the material at macro-scale, the SHPB experiments were conducted. The experimental results were then used to build a constitutive model as an input to the material model used in numerical simulations.

The procedures followed in SHPB experiments to obtain the strain, strain-rate and flow stress in the specimen are based on some basic assumptions. The detailed 3-D numerical analysis of the SHPB experiment demonstrated that an assumption of homogeneity of stress and strain fields in the specimen is not satisfied at the early stages of the compression process at room temperature. Hence, the validity of such assumptions should be critically assessed for each combination of material, temperature and high-strain-rate loading conditions.

\section{Acknowledgement}

Authors would like to acknowledge Tõnu Leemet at Tampere University of Technology for providing the material data for the Ti-based alloy. Funding from the European Union Seventh Framework Programme (FP7/2007-2013) under grant agreement No. PITN-GA-2008-211536, project MaMiNa is gratefully acknowledged.

\section{References}

[1] C. Leyens and M. Peters (eds.): Titanium and Titanium Alloys - Fundamentals and Applications, Wiley VCH, (2003)

[2] H. Kolsky: An investigation of the mechanical properties of materials at very high rates of loading. Proc. Phys. Soc. B62 (1949), p. 676-700

[3] H. Zhao and G. Gary: On the use of SHPB techniques to determine the dynamic behavior of materials in the range of small strains. Int. J. Solids Structures, 33 (23) (1996), p. 3363

[4] W. Chen, B. Song, D. Frew and M. Forrestal: Dynamic small strain measurements of a metal specimen with a Split Hopkinson Pressure Bar. Exp. Mech., 43 (1) (2002), p. 20

[5] L. M. Yang and V. P. W. Shim: An analysis of stress uniformity in split Hopkinson bar test specimens. Int. J. Imp. Eng. 31 (2) (2005), p. 129

[6] E. D. H. Davies and S. C. Hunter: The dynamic compression testing of solids by the method of the split Hopkinson pressure bar. J. Mech. Phys. Solids 11 (1963), p. 155

[7] J. F. Bell: An experimental diffraction grating study of the quasi-static hypothesis of the split Hopkinson bar experiment. J. Mech. Phys. Solids 14 (1966), p. 309

[8] T. Vuoristo and V.-T. Kuokkala: Creep, recovery and high strain rate response of soft roll cover materials. Mech. Mater. 34 (8) (2002), p. 493

[9] M. Hokka: Mechanical testing of materials with the Hopkinson Split Bar technique. Proceedings of the SMP IX Conference, Lappeenranta, Finland (2006)

[10] Z. Li and J. Lambros: Determination of the dynamic response of brittle composites by the use of the split Hopkinson pressure bar. Compos. Sci. Technol. 59 (7) (1999), p. 1097

[11] M. Hokka: Effects of Strain Rate and Temperature on the Mechanical Behavior of Advanced High Strength Steels. Ph.D. thesis, Department of Materials Science, Tampere University of Technology, 2008

[12] MSC. Marc User's Guide, Version 2008r1, MSC Software Corporation, Los Angeles, 2008

[13] M. Demiral, A. Roy and V.V. Silberschmidt: Effects of loading conditions on deformation process in indentation. Comp. Mater. \& Cont. 19 (2) (2010), p.199 